\title{
Liverworts frequently form mycothalli on Spitsbergen in the High Arctic
}

\author{
Kevin K. Newsham ${ }^{1}$ \& William P. Goodall-Copestake ${ }^{1,2}$ \\ ${ }^{1}$ British Antarctic Survey, Natural Environment Research Council, Cambridge, UK; \\ ${ }^{2}$ Scottish Association for Marine Science, Oban, Argyll, Scotland, UK
}

\begin{abstract}
Mycothalli, symbioses between liverworts and soil fungi, have not previously been recorded in the Arctic. Here, 13 species of leafy liverwort from west Spitsbergen in the High Arctic are examined for the symbiosis using epifluorescence microscopy and sequencing of fungal ribosomal $(r)$ RNA genes amplified from plant tissues. Microscopy showed that intracellular hyphal coils, key indicators of the symbiosis, were frequent ( $>40 \%$ stem length colonized) in nine species of liverwort in the families Anastrophyllaceae, Lophoziaceae, Cephaloziellaceae, Cephaloziaceae and Scapaniaceae, with hyphae occurring frequently ( $>40 \%$ cells occupied) in the rhizoids of 10 species in the same families. Dark septate hyphae, apparently formed by ascomycetes, were frequent on the stems of members of the Anastrophyllaceae, Cephaloziellaceae and Cephaloziaceae, and typically those growing on acidic mine tailings. Sequencing of fungal $r$ RNA genes showed the presence of nine distinct groups (based on a $3 \%$ cut-off for ITS sequence divergence) of the basidiomycete Serendipita in the Anastrophyllaceae and Lophoziaceae, with ordinations and correlative analyses showing the presence of the genus to be positively associated with the frequency of hyphal coils, the occurrence of which was positively associated with edaphic factors (soil $\delta^{15} \mathrm{~N}$ value and concentrations of moisture, nitrogen, carbon and organic matter). We propose that the frequency of mycothalli in leafy liverworts on west Spitsbergen, which is an order of magnitude higher than at lower latitudes, may arise from benefits conferred by mycobionts on their hosts in the harsh environment of the High Arctic.
\end{abstract}

To access the supplementary material, please visit the article landing page

\section{Keywords}

Edaphic factors; Jungermanniidae; leafy liverworts; Serendipita; Svalbard; symbiosis

\section{Correspondence}

Kevin Newsham, British Antarctic Survey, Natural Environment Research Council, High Cross, Cambridge CB3 OET, UK. E-mail: kne@ bas.ac.uk

\section{Abbreviations \\ BLAST: basic local alignment search tool DS: dark septate \\ GLM: general linear model \\ ITS: internal transcribed spacer \\ MUSCLE: multiple sequence comparison by log-expectation \\ PCA: principal components analysis \\ PCR: polymerase chain reaction \\ SLC: stem length colonized}

\section{Introduction}

The harsh environmental conditions encountered in polar terrestrial ecosystems exert strong selection pressures on plants and other autotrophs, with low temperatures, aridity and high wind speeds leading to the occurrence of prostrate angiosperms, reduced species diversity and increased abundances of cryptogams (Newsham et al. 2009; Wietrzyk-Pełka et al. 2020). Symbioses occur frequently under these selection pressures, with algae and cyanobacteria entering into mutualisms with fungi to form lichens, which routinely dominate land cover in arid ecosystems at high latitudes (Asplund $\&$ Wardle 2017). Angiosperms similarly enter into mutualisms with soil fungi, predominantly not only to enhance the uptake of growth-limiting nutrients into their roots via fungal hyphae but also to benefit from improved antioxidant activity and osmotic balance derived from colonization by symbiotic fungi, which confer cold and freezing tolerance on the host (Acuña-Rodríguez et al. 2020). Accordingly, each of the main fungal symbionts associated with the roots of angiosperms at lower latitudes is present in the Arctic, with ecto-, ericoid, arbuscular, arbutoid and even orchid mycorrhizas having been recorded across the region (Newsham et al. 2009).

Research in temperate, tropical and Antarctic ecosystems indicates that members of all of the major liverwort clades form symbioses with soil fungi (Boullard 1988; Rimington et al. 2020). These symbioses, termed mycothalli, bear structural similarities to mycorrhizas: broadly, as in the arbuscular mycorrhizal mutualism, arbuscules and vesicles form in the tissues of the 
earlier-diverging complex thalloid and simple thalloid I liverworts, whereas septate intracellular hyphal coils, similar to the pelotons formed in orchid mycorrhizas, develop in the stem cells and rhizoid bases of more recently derived simple thalloid II and leafy liverwort species (Read et al. 2000; Bidartondo \& Duckett 2010). Intracellular coils, which are the defining features of the symbiosis in the latter two clades, are usually accompanied by extensive hyphal colonization of rhizoid cells (Read et al. 2000; Pressel et al. 2010). Although complex thalloid and simple thalloid I and II liverwort species are typically infrequent in polar regions, the leafy liverworts have pan-Arctic distributions and can be locally abundant, particularly in mesic habitats (Arnell \& Mårtensson 1959; Frisvoll \& Elvebakk 1996; Konstantinova 2000; Damsholt 2007, 2013; Hassel et al. 2014). A range of fungi, known as mycobionts, colonize the leafy liverworts, with basidiomycetes (recently transferred from Sebacinales clade B to the Serendipitaceae [Weiß et al. 2016]) forming symbioses with members of families such as the Lophoziaceae, Scapaniaceae and Anastrophyllaceae (Read et al. 2000; Bidartondo \& Duckett 2010) and ascomycetes-often the ericoid mycorrhizal symbiont Pezoloma ericae-associating with members of the families Cephaloziaceae and Cephaloziellaceae (Upson et al. 2007; Kowal et al. 2018). In contrast with the mycorrhizas, in which the main role of the symbiosis in soil nutrient acquisition is firmly established (Read 1991), the functions of mycothalli remain relatively obscure (Read et al. 2000; Weiß et al. 2016). However, recent research indicates that as in the ericoid mycorrhizal association, P. ericae enhances the nutrient uptake of Cephalozia bicuspidata, a leafy liverwort species (Kowal et al. 2018).
To the best of our knowledge, there are no reports in the literature of mycothalli from north of the Arctic Circle, with the northernmost record of the symbiosis apparently being in the simple thalloid I liverwort species Fossombronia incurva and F. wondraczekii on western Iceland at $64{ }^{\circ} \mathrm{N}$ (Rimington et al. 2019). Here, in order to determine whether or not mycothalli are present in the Arctic, we report a survey for the symbiosis in leafy liverworts on west Spitsbergen. The aims of the survey were to determine, using epifluorescence microscopy, the distribution of mycobionts in the tissues of 13 locally abundant leafy liverwort species and to taxonomically place frequently occurring mycobionts by sequencing fungal ribosomal RNA genes amplified from liverwort tissues. By comparing the frequencies of fungal structures in liverwort tissues with the occurrence of different fungal taxa, we also aimed to evaluate whether specific structures might be formed by distinct taxa of fungi. Furthermore, given the previous observation that symbioses between leafy liverworts and basidiomycetes tend to occur on soils high in organic matter (Duckett et al. 2006; Bidartondo \& Duckett 2010), we also determined whether the frequency of intracellular hyphal coils is associated with edaphic factors.

\section{Materials and methods}

\section{Site descriptions and sampling}

Locally abundant leafy liverworts were sampled from eight sites on Brøggerhalvøya and Blomstrandhalvøya, on the west coast of Spitsbergen in the High-Arctic archipelago of Svalbard (Fig. 1). Details and images of the sampling sites are shown in Supplementary Table S1 and Supplementary
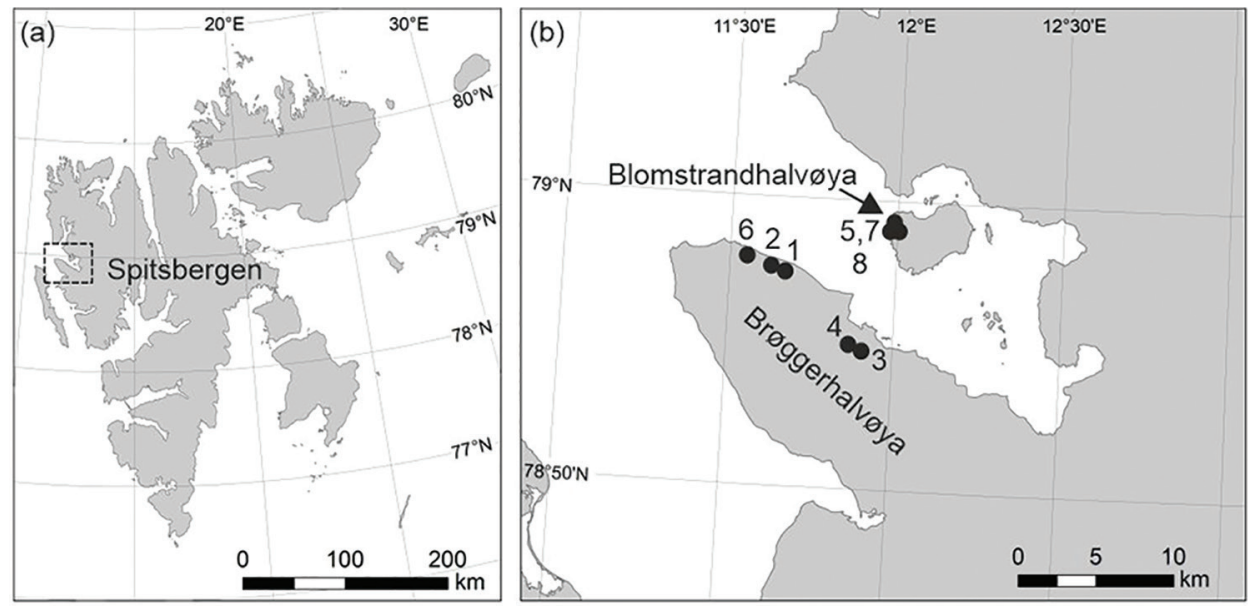

Fig. 1 Maps showing the locations of (a) Spitsbergen in the High-Arctic archipelago of Svalbard and (b) Brøggerhalvøya and Blomstrandhalvøya, with the positions of the eight sampling sites marked. See Supplementary Fig. S1 and Supplementary Table S1 for images and further details of the sampling sites. 
Fig. S 1, respectively. Mean annual and winter and summer air temperatures on Brøggerhalvøya are $-5.7^{\circ} \mathrm{C},-12.7^{\circ} \mathrm{C}$ and $3.7^{\circ} \mathrm{C}$, respectively, and mean annual precipitation is $409 \mathrm{~mm}$, most of which falls as snow (Hanssen-Bauer et al. 2019). The snow-free season on Brøggerhalvøya lasts for about 90 days, with snow cover accumulating from mid-September, and most having melted by mid-June (Winther et al. 2002; Beck et al. 2005). The sun remains below the sea-level horizon on Brøggerhalvøya between 25 October and 17 February (Winther et al. 2002).

In July 2010, August 2011 and July 2012, 140 specimens of 13 leafy liverwort species in the Anastrophyllaceae, Cephaloziaceae, Cephaloziellaceae, Lophoziaceae, Scapaniaceae, Blepharostomataceae and Ptilidiaceae (Table 1) were collected from the eight sites. Using a clean spatula, soil (depth 0-20 mm) was also sampled from directly beneath each liverwort specimen. The specimens, which were air-dried at room temperature within several hours of collection in a clean paper packet, have been deposited in the British Antarctic Survey herbarium (Index Herbariorum code AAS; see https://data.bas. ac.uk/metadata.php?id=GB/NERC/BAS/AEDC/00023).

\section{Edaphic factors}

Soil $\mathrm{pH}$ value was measured by adding approximately the same volume of deionized water to fresh soils to generate slurries and recording $\mathrm{pH}$ after 10 minutes using a glass electrode ( $\mathrm{pH} 21$, Hanna Instruments). Moisture concentration was measured by heating ca. $1 \mathrm{~g}$ of fresh sub-samples of soils to constant weight at $105^{\circ} \mathrm{C}$. The remaining soils were airdried prior to further analyses. Organic matter concentration was determined by heating sub-samples of the air-dried

Table 1 Liverwort taxa sampled from Brøggerhalvøya and Blomstrandhalvøya.

\begin{tabular}{ll}
\hline Family $^{\text {a }}$ & Species $^{\text {a,b }}$ \\
\hline Anastrophyllaceae & Barbilophozia hatcheri (8) \\
& Gymnocolea inflata (6) \\
& Pseudolophozia sudetica (7) \\
& Schljakovianthus quadrilobus (12) \\
& Sphenolobus minutus (10) \\
& Cephalozia bicuspidata (4) \\
Cephaloziaceae & Cephaloziella varians ${ }^{(18)}$ \\
Cephaloziellaceae & Lophoziopsis excisa (18) \\
Lophoziaceae & Lophozia wenzelii (2) \\
& Trilophozia quinquedentata (33) \\
Scapaniaceae & Scapania undulata (3) \\
Blepharostomataceae & Blepharostoma trichophyllum (10) \\
Ptilidiaceae & Ptilidium ciliare (9) \\
\hline
\end{tabular}

${ }^{a}$ Taxonomy follows Söderström et al. (2016). ${ }^{\text {b }}$ Values in parentheses indicate the numbers of samples of each species examined by microscopy. 'Syn. Cephaloziella arctica (Stotler \& Crandall-Stotler 2017). soils to $550{ }^{\circ} \mathrm{C}$ in a muffle furnace for 4 hours prior to cooling over desiccant and weighing. Air-dried soils (ca. $2.5 \mathrm{mg}$ ) were also weighed into tin capsules and analysed for total carbon concentration, $\delta^{13} \mathrm{C}$ value, total nitrogen concentration and $\delta^{15} \mathrm{~N}$ value using a PDZ Europa ANCA-GSL elemental analyser interfaced to a PDZ Europa 20-20 isotope ratio mass spectrometer (Sercon Ltd.) at the University of California-Davis stable isotope facility.

\section{Distribution of mycobionts}

Dried plants were rehydrated in water and cleared in $10 \%$ potassium hydroxide for 24 hours at room temperature. All plants were then rinsed thoroughly with water and were bleached in a mixture of 30\% hydrogen peroxide and 3\% ammonium hydroxide (10:1, v/v) for up to 10 minutes. The plants were then washed thoroughly with water, were acidified in $5 \%$ lactic acid for 1 hour and were stained with $0.01 \%$ aniline blue in lactic acid for 24 hours. They were then removed from the staining solution, excess stain was drawn off on absorbent paper and the plants were destained for at least 24 hours in $80 \%$ lactic acid. Between 10 and 15 healthy stems of each species, and at least 40 of those of Cephaloziella varians and Cephalozia bicuspidata, were then lightly squashed in $80 \%$ lactic acid on glass slides prior to observation under epifluorescence at $\times 400$ magnification using a BX51 compound microscope fitted with a UPlanApo $\times 40$ objective lens, a 100-W mercury short arc lamp and an ultraviolet fluorescence filter cube (U-MWU2, consisting of a BP 330-385 excitation filter, a DM 400 dichromatic mirror and an LP 420 emission filter; Olympus Life Science). Between 50 and 135 (mean 102) intersections were scored for stained (and hence fluorescing) intracellular hyphal coils in rhizoid bases and stem epidermal cells, stained septate hyphae on stem surfaces and DS hyphae on stem surfaces, with the percentage of SLC by each of these structures subsequently being calculated (McGonigle et al. 1990). If $\geq 30$ rhizoids were present, then the percentage that were colonized by hyphae was also determined. The data derived from these analyses have been deposited in the UK Polar Data Centre (https://doi.org/10.5285/80DE87F3-9497-46 06-8C7D-3293AB05651F).

\section{Taxonomic placement of mycobionts}

Fungal DNA was amplified from 26 of the 140 specimens. These consisted of 1-3 specimens of each of the 13 species collected from the eight sampling sites (Supplementary Table S2). Visibly healthy plants were sorted to single species and were cleaned of any debris in water under a binocular microscope at $\geq \times 7.5$ magnification. Using a modification of the root washing method of Harley $\&$ Waid (1955), the plants were then surface sterilized using 
30 washes of sterile water $(10 \mathrm{ml})$ in sterile tubes $(15 \mathrm{ml}$ capacity) on a vortexer set to maximum speed ( 50 revolutions per second). Treatment with sodium hypochlorite or other surface sterilants was avoided at this step because the stems of some of the liverwort species studied are only a few cells in thickness. Water was drained from plants on sterile plastic mesh $(1 \mathrm{~mm})$ between washes, each of which lasted for 5 minutes. After washing, the tissues were blotted dry on sterile filter paper and were then air-dried for 60 minutes under a sterile hood. They were then rehydrated in sterile water and homogenized with a TissueRuptor (Qiagen).

DNA was extracted from washed liverwort tissues using an Extract'n'Amp kit (Sigma-Aldrich) following the manufacturer's instructions, again under a sterile hood. A commercially available reagent mix (MyTaqHS, Bioline Reagents Ltd) was used to amplify fungal DNA from liverwort tissues. Reactions, made up to $15 \mu \mathrm{l}$ with sterile distilled water, contained a $0.25 \mu \mathrm{M}$ final concentration of each of the primers ITSIF (5'-CTTGGTCATTTAGAGGAGTAA-3'; Gardes \& Bruns 1993) and ITS4 (5'-TCCTCCGCTTATTGATATGC-3'; White et al. 1990). The DNA template used in these reactions was a $0.75 \mu \mathrm{l}$ aliquot of the final Extract'n'Amp mixture, or sterile distilled water as a negative control. PCR thermocycling was carried out using an initial denaturation of $95{ }^{\circ} \mathrm{C}$ for 5 minutes, followed by 35 cycles of denaturation at $95{ }^{\circ} \mathrm{C}$ for 15 seconds, annealing at $56{ }^{\circ} \mathrm{C}$ for 15 seconds, and elongation at $72{ }^{\circ} \mathrm{C}$ for 2 minutes, with a final elongation step of 5 minutes. Gel visualization indicated a strong amplification of ITS regions from the extracts from liverwort tissues and no amplicons from negative controls. The ITS region PCR products were cloned using a TOPO TA Cloning Kit (Thermo Fisher Scientific), and the cloned DNA was subsequently amplified using the MI3F (5'-GTAAAACGACGGCCAG-3') and MI3R (5'-AACAGCTATGACCATGAT-3') primer set and was bidirectionally sequenced using these Ml3 primers at a commercial facility. Forward and reverse chromatograms from each clone were assembled, base calling within the resulting contig was verified and vector and primer sequences were trimmed using Geneious Prime 2019.2.3 (http://www.geneious.com, accessed December 2019). Sequences of $<400$ base pairs and with relative abundances of $<5 \%$ were excluded from further analyses, resulting in a total of 284 high-quality sequences, with 10-39 (mean 22) sequences per liverwort species.

The sequences were aligned using the MUSCLE algorithm implemented in Geneious with output grouped according to similarity. Ribosomal RNA-encoding and ITS spacer regions were then defined based on homology to similar fungal sequences identified through the BLAST function in Geneious with the default nr/nt National
Center for Biotechnology Information database setting. In order to delineate putative fungal species boundaries between the sequences, Geneious was used iteratively, to define and realign sub-groups of sequences until within-group ITS divergences were $<3 \%$, following the rationale of Blaalid et al. (2013). The taxonomic placement of representative sequences from each putative species group was then determined using the massBLASTer function in UNITE version 8.2 (release date February 2020), a curated database of fungal ITS sequences (Nilsson et al. 2015). The closest named match below the kingdom level was selected for each sequence and was used to define taxonomic identifiers that were consistent with the percentage match identity (i.e., matches to species, genus, family, order and class levels of $>97 \%,>90 \%,>85 \%$, $>80 \%$ and $>75 \%$, respectively).

\section{Statistical analyses}

PCA was used to determine associations between the frequencies of fungal structures and taxa in the 26 specimens from which DNA was amplified, and GLMs were used to determine differences between the frequencies of fungal structures in the tissues of specimens in which different fungal taxa were recorded. Pearson's correlations were also used to determine associations between the frequencies of hyphal coils in members of the Anastrophyllaceae and Lophoziaceae and edaphic factors. Statistical analyses were performed in MINITAB 19 (State College, PA, USA).

\section{Results}

\section{Distribution of mycobionts}

Stained hyphal coils formed in the rhizoid bases and stem medullary cells of 12 of the 13 leafy liverwort species that were examined (Fig. 2a). The coils were typically formed by tightly convoluted, septate hyphae of ca. 1.5-2.0 $\mu \mathrm{m}$ width (Supplementary Fig. S2a-c). Hyphal coils were frequent ( $>40 \%$ SLC) in the tissues of nine leafy liverwort species (Barbilophozia hatcheri, Pseudolophozia sudetica, Sphenolobus minutus, Cephalozia bicuspidata, Cephaloziella varians, Lophoziopsis excisa, Lophozia wenzelii, Trilophozia quinquedentata and Scapania undulata), with these structures being particularly frequent in all three members of the Lophoziaceae and in those of the Anastrophyllaceae, except for Gymnocolea inflata and Schljakovianthus quadrilobus (Fig. 2a). In contrast, hyphal coils were infrequent (2\% SLC) in the tissues of Blepharostoma trichophyllum and were not recorded in those of Ptilidium ciliare (Fig. 2a). Rhizoid colonization followed a similar pattern, with frequent colonization ( $>40 \%$ of rhizoids colonized) in 10 liverwort 

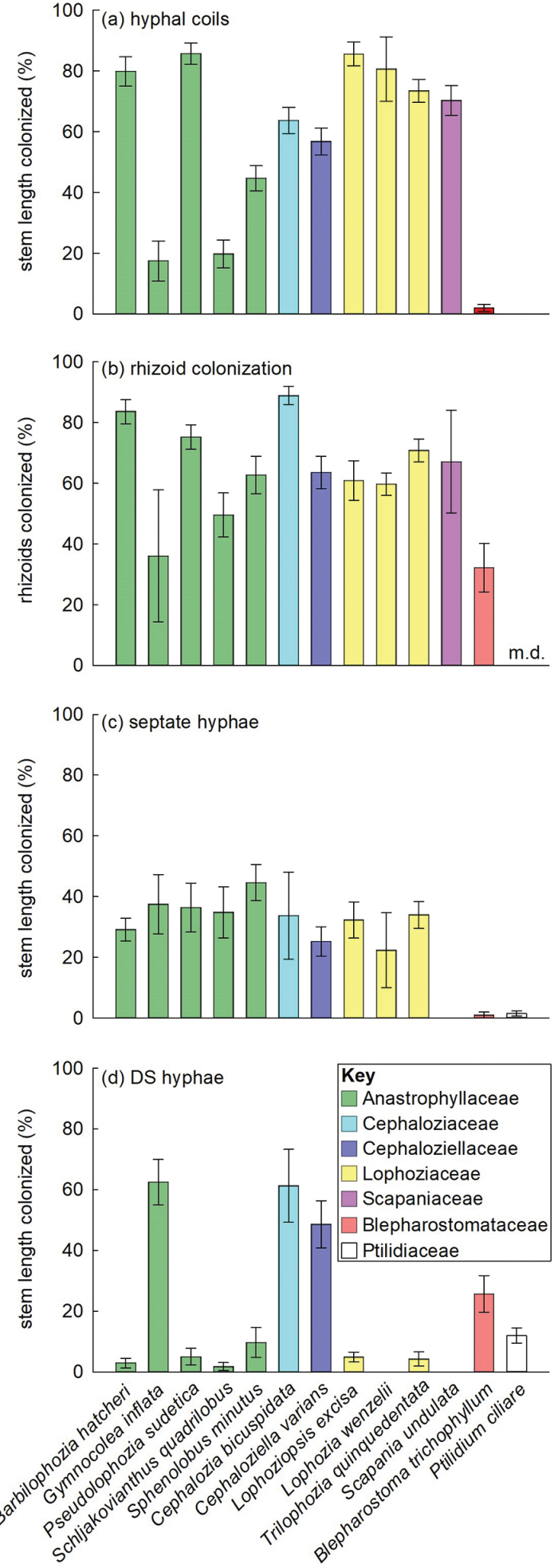

Fig. 2 Percentages of (a) SLC by hyphal coils, (b) rhizoids colonized by hyphae (the abbreviation m.d. indicates that rhizoids were not observed), (c) SLC by septate hyphae and (d) SLC by DS hyphae in leafy liverworts sampled from Brøggerhalvøya and Blomstrandhalvøya. See Table 1 for details of replication. Bars are standard errors of the means. species, including all members of the Lophoziaceae and all but one member of the Anastrophyllaceae ( $G$. inflata; Fig. $2 \mathrm{~b})$, by septate hyphae continuous with hyphal coils in the bases of rhizoid cells (Supplementary Fig. S2d). As for coils, hyphae were relatively infrequent in the rhizoids of B. trichophyllum ( $32 \%$ of cells colonized), and rhizoids were apparently absent from the stems of $P$. ciliare (Fig. 2b). Stained septate hyphae on stem surfaces were less frequent than hyphal coils and colonized rhizoids, with these hyphae only being frequent ( $>40 \%$ SLC) on the stems of $S$. minutus (Fig. 2c). DS hyphae, which often occurred on the surfaces of stems colonized by other fungal structures (Supplementary Fig. S2e), varied substantially in abundance, with frequent ( $>40 \%$ SLC) occurrence on individual members of the Anastrophyllaceae, Cephaloziaceae and Cephaloziellaceae (G. inflata, C. bicuspidata and C. varians, respectively; Fig. 2d).

\section{Taxonomic placement of mycobionts}

The DNA of ascomycetes and basidiomycetes was amplified from the 26 specimens of liverworts sampled from Brøggerhalvøya and Blomstrandhalvøya (Table 2). All of the ascomycetes belonged to the subphylum Pezizomycotina and had ITS region sequences that were $89-99 \%$ similar to those of fungi previously recorded from roots, soils and ascocarps from North America and Europe (Table 2). Two groups of Cladophialophora, referred to below as Cladophialophora_A and Cladophialophora_B, along with Cheilymenia, Bryochiton and members of the Lecanoromycetes, Leotiomycetes, Dothideomycetes, Chaetothyriales and Helotiales, including Pezoloma ericae, were recorded (Table 2). The most frequent ascomycete, which accounted for $23 \%$ of all DNA reads, was a member of the Leotiomycetes. It was recorded in four liverwort species (C. varians, C. bicuspidata, G. inflata and S. undulata), the latter three of which were exclusively sampled from acidic ( $\mathrm{pH} 4.5$ ) mine tailings (Supplementary Table S1). Three members of the Helotiales were recorded, with Pezoloma ericae being amplified from B. hatcheri, S. quadrilobus and S. minutus (10-24\% of reads in each liverwort species), and two other members of the order from $T$. quinquedentata and P. ciliare (Fig. 3). A representative of the Dothideomycetes was recovered from C. varians, C. bicuspidata and G. inflata, and Cheilymenia was found in L. excisa (Fig. 3). A species of Bryochiton was detected in P. ciliare, with members of the Lecanoromycetes and Chaetothyriales being identified in B. trichophyllum and the latter fungus also being found in S. quadrilobus (Fig. 3). Cladophialophora_A was amplified from $B$. hatcheri and $L$. wenzelii and Cladophialophora_B from G. inflata (8-35\% of reads; Fig. 3).

The basidiomycetes consisted of nine groups of Serendipita, which accounted for $41 \%$ of all DNA reads and are referred to below as Serendipita_A-I, along with a 
Table 2 The taxa of fungi recorded in leafy liverworts sampled from Brøggerhalvøya and Blomstrandhalvøya. Distinct taxa are classified based on a 3\% cut-off for ITS sequence divergence.

\begin{tabular}{|c|c|c|c|c|}
\hline Fungal taxon & $\begin{array}{l}\text { GenBank accession } \\
\text { code }\end{array}$ & $\begin{array}{l}\text { Closest named GenBank match } \\
\text { (percentage identity, accession } \\
\text { code, source and continent) }\end{array}$ & $\begin{array}{l}\text { Closest UNITE species } \\
\text { hypothesis }\end{array}$ & Lineage \\
\hline \multicolumn{5}{|l|}{ Ascomycota } \\
\hline (1) Cladophialophora_A & MW257161 & 99\%, HQ211827, soil, North America & SH1616354.08FU & $\begin{array}{l}\text { Pezizomycotina; Eurotiomycetes; Cha- } \\
\text { etothyriomycetidae; Chaetothyriales; } \\
\text { Herpotrichiellaceae }\end{array}$ \\
\hline (2) Cladophialophora_B & MW257162 & 95\%, HQ211827, soil, North America & SH1616354.08FU & As for Cladophialophora_A \\
\hline (3) Lecanoromycetes & MW257163 & 95\%, HQ212081, soil, North America & SH1566020.08FU & Pezizomycotina \\
\hline (4) Helotiales & MW257164 & $99 \%$, KC965767, soil, North America & SH1557921.08FU & $\begin{array}{l}\text { Pezizomycotina; Leotiomycetes; } \\
\text { Leotiomycetidae }\end{array}$ \\
\hline (5) Leotiomycetes & MW257165 & 89\%, HQ212060, soil, North America & SH1544362.08FU & Pezizomycotina \\
\hline (6) Cheilymenia & MW257166 & 97\%, KF617920, soil, North America & m.d. ${ }^{b}$ & $\begin{array}{l}\text { Pezizomycotina; Pezizomycetes; Pezizo- } \\
\text { mycetidae; Pezizales; Pyronemataceae }\end{array}$ \\
\hline (7) Dothideomycetes & MW257167 & 93\%, EU292643, soil, North America & SH1565780.08FU & Pezizomycotina \\
\hline (8) Chaetothyriales & MW257168 & $98 \%$, GU581246, grass root, Europe & SH1565801.08FU & $\begin{array}{l}\text { Pezizomycotina; Eurotiomycetes; } \\
\text { Chaetothyriomycetidae }\end{array}$ \\
\hline (9) Bryochiton ${ }^{a}$ & MW257169 & 93\%, MH864237, ascocarp, Europe & SH1571463.08FU & $\begin{array}{l}\text { Pezizomycotina; Dothideomy- } \\
\text { cetes; Dothideomycetes i.s.c; } \\
\text { Pseudoperisporiaceae }\end{array}$ \\
\hline (10) Helotiales & MW257170 & 92\%, GU366730, soil, North America & SH1565558.08FU & $\begin{array}{l}\text { Pezizomycotina; Leotiomycetes; } \\
\text { Leotiomycetidae }\end{array}$ \\
\hline (11) Pezoloma ericae & MW257171 & 99\%, HQ212326, soil, North America & SH1523755.08FU & $\begin{array}{l}\text { Pezizomycotina; Leotiomycetes; Leotio- } \\
\text { mycetidae; Helotiales; Leotiaceae }\end{array}$ \\
\hline \multicolumn{5}{|l|}{ Basidiomycota } \\
\hline (12) Serendipita_A & MW257173 & $\begin{array}{l}\text { 98\%, GQ907084, Barbilophozia } \\
\text { lycopodioides, Europe }\end{array}$ & SH1577252.08FU & $\begin{array}{l}\text { Agaricomycotina; Agaricomycetes; } \\
\text { Agaricomycetes i.s. '; Sebacinales; } \\
\text { Serendipitaceae }\end{array}$ \\
\hline (13) Serendipita_B & MW257174 & $\begin{array}{l}\text { 97\%, GQ907137, Lophozia crispata, } \\
\text { South America }\end{array}$ & SH1577346.08FU & As for Serendipita_A \\
\hline (14) Serendipita_C & MW257175 & $\begin{array}{l}\text { 99\%, GQ907137, L. crispata, South } \\
\text { America }\end{array}$ & SH1577346.08FU & As for Serendipita_A \\
\hline (15) Serendipita_D & MW257176 & $\begin{array}{l}\text { 95\%, GQ907141, Saccogyna viticulosa, } \\
\text { Europe }\end{array}$ & SH1577377.08FU & As for Serendipita_A \\
\hline (16) Serendipita_E & MW257177 & $\begin{array}{l}\text { 94\%, GQ907108, Lophozia sudetica, } \\
\text { Europe }\end{array}$ & SH1577429.08FU & As for Serendipita_A \\
\hline (17) Serendipita_F & MW257178 & $\begin{array}{l}\text { 95\%, GQ907091, Scapania calcicola, } \\
\text { Europe }\end{array}$ & SH1577319.08FU & As for Serendipita_A \\
\hline (18) Serendipita_G & MW257179 & $\begin{array}{l}\text { 99\%, GQ907107, Lophozia opacifolia, } \\
\text { Europe }\end{array}$ & SH1577320.08FU & As for Serendipita_A \\
\hline (19) Serendipita_H & MW257180 & $\begin{array}{l}\text { 98\%, GQ907111, Scapania irrigua, } \\
\text { Europe }\end{array}$ & SH1577350.08FU & As for Serendipita_A \\
\hline (20) Serendipita_I & MW257181 & $\begin{array}{l}\text { 93\%, GQ907082, Lophozia wenzelii, } \\
\text { Europe }\end{array}$ & SH1577354.08FU & As for Serendipita_A \\
\hline (21) Sebacinales & MW257182 & $\begin{array}{l}\text { 97\%, GQ907149, Trilophozia quin- } \\
\text { quedentata, Europe }\end{array}$ & SH1577384.08FU & $\begin{array}{l}\text { Agaricomycotina; Agaricomycetes; } \\
\text { Agaricomycetes i.s. }\end{array}$ \\
\hline
\end{tabular}

${ }^{a} \mathrm{MH} 864237$, deposited as Bryochiton perpusillus, is named only to genus level, reflecting the uncertainty surrounding the $93 \%$ level match. ${ }^{b} \mathrm{Missing}$ data. Incertae sedis.

representative of the Sebacinales (Table 2). The ITS regions of each of these fungi bore $93-99 \%$ similarities to those of previously reported mycobionts of leafy liverworts from
Europe and South America (Table 2). The DNA of Serendipita_A-I and the Sebacinales was only amplified from liverworts belonging to the Anastrophyllaceae and 

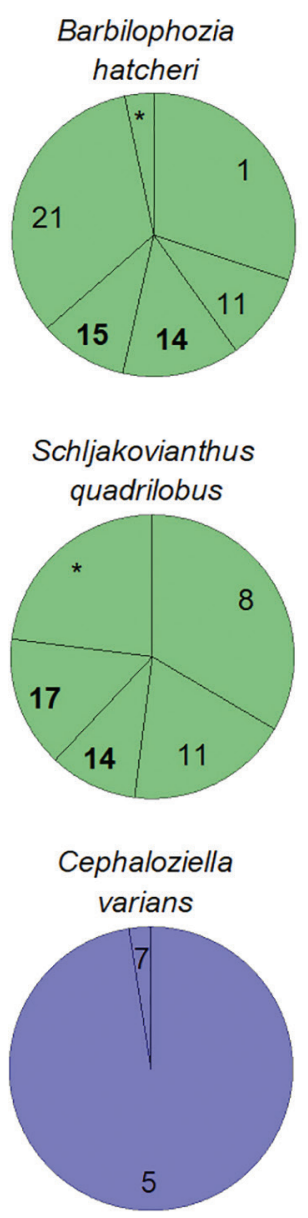

Trilophozia quinquedentata
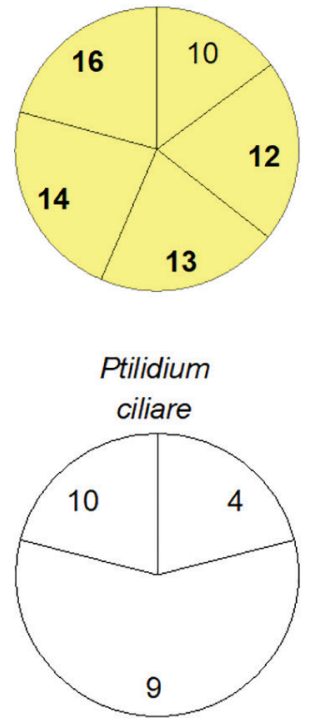
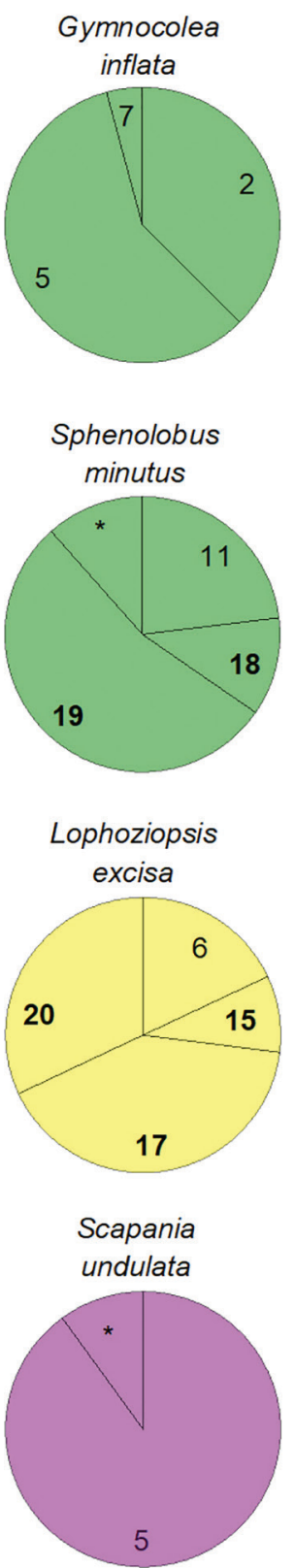

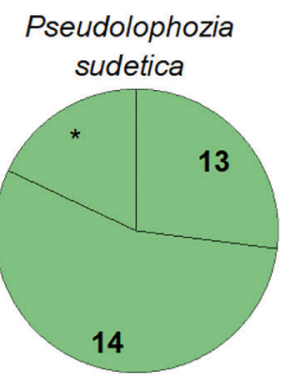

Cephalozia

bicuspidata

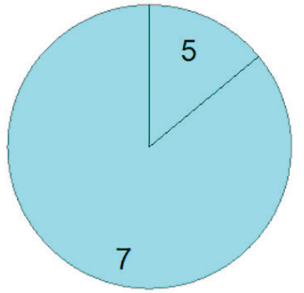

Lophozia

wenzelii

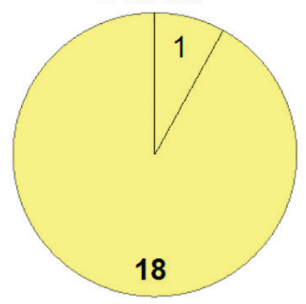

Blepharostoma

trichophyllum

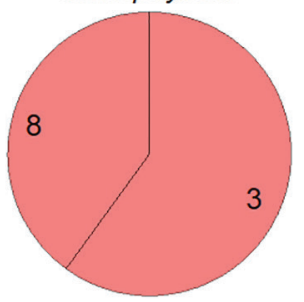

Fig. 3 Pie charts showing the taxa of fungi amplified from leafy liverworts sampled from Brøggerhalvøya and Blomstrandhalvøya. The numbers in each segment correspond to those shown in the first column of Table 2. Segments marked with asterisks indicate fungal taxa present at relative abundances of $<5 \%$ across the entire data set. Numbers between 12 and 20 , in boldface, denote Serendipita_A-I. 
Lophoziaceae and was frequently amplified from B. hatcheri, P. sudetica, S. minutus, L. excisa, L. wenzelii and T. quinquedentata, in which it accounted for $55-92 \%$ of reads (Fig. 3). Between one and four distinct groups of Serendipita were recorded in each of these species (Fig. 3). These fungi accounted for fewer DNA reads in $S$. quadrilobus (Anastrophyllaceae), with Serendipita_C and Serendipita_F collectively accounting for a quarter of reads amplified from the tissues of this species (Fig. 3). The only member of the Anastrophyllaceae or Lophoziaceae from which the DNA of Serendipita or the Sebacinales was not amplified was $G$. inflata (Fig. 3).

\section{Structures as predictors of mycobiont identity}

Analyses using GLMs indicated that hyphal coils (Supplementary Fig. S2a-c) were almost twice as frequent in specimens from which the DNA of Serendipita_A-I was amplified than in those from which the basidiomycete was apparently absent (mean SLC by coils $=65.8 \%$ and $37.5 \%$, respectively; $F_{1,46}=12.88, p=0.002$ ). PCA similarly indicated positive associations between the frequencies of hyphal coils and the occurrence of Serendipita in members of the Anastrophyllaceae and Lophoziaceae (Fig. 4). In particular, the presence of Serendipita A-D and

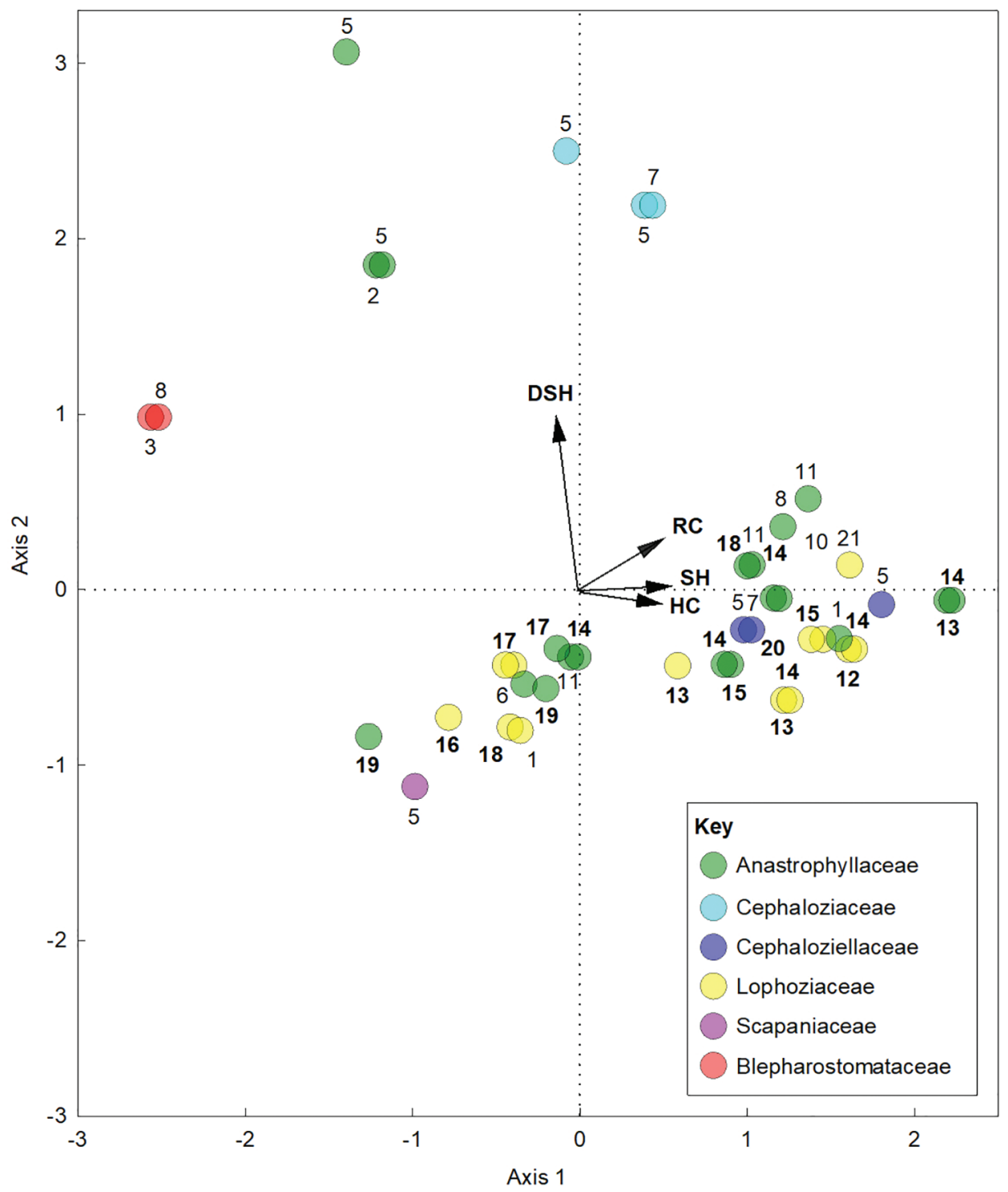

Fig. 4 PCA biplot showing associations between fungal structures and the identities of mycobionts colonizing leafy liverworts. Fungal taxa are denoted by numbers, corresponding to those in the first column of Table 2. Numbers between 12 and 20, in boldface, denote Serendipita_A-I. Arrows denote vectors: dark septate hyphae (DSH); rhizoid colonization (RC); septate hyphae (SH); hyphal coils (HC). Note that axes 1 and 2 collectively explained 83.5\% of variation, and that the lack of rhizoids on the stems of Ptilidium ciliare precluded its inclusion in the PCA. 
Serendipita_I was strongly associated with the formation of hyphal coils in liverwort tissues (Fig. 4), with coils being abundant (mean SLC $=77-95 \%$ ) in liverwort specimens from which the DNA of these five mycobionts was amplified. GLMs also indicated more frequent hyphal colonization of rhizoids (Supplementary Fig. S2d) in specimens from which the DNA of Serendipita_A-I was amplified compared with those from which the DNA of the genus was not amplified (mean colonization $=70.9 \%$ and $51.4 \%$, respectively; $F_{1,46}=4.83, p=0.033$ ). PCA similarly showed positive associations between rhizoid colonization and the frequencies of Serendipita (Fig. 4), with 79-94\% of rhizoid cells being colonized by hyphae when the DNA of Serendipita_B-D and Serendipita_I was amplified from specimens. PCA also suggested that the frequency of septate hyphae on stem surfaces was positively associated with the presence of Serendipita (Fig. 4), with $45-60 \%$ of stem length occupied by these hyphae when the DNA of Serendipita A-C and Serendipita_F was amplified from liverwort specimens. However, there was only a marginally significant difference between the frequency of septate hyphae on stem surfaces of specimens from which the DNA of
Serendipita_A-I was amplified and specimens apparently not colonized by these fungi $\left(F_{1,46}=3.55, p=0.066\right)$.

GLMs showed less frequent colonization by DS hyphae in specimens from which the DNA of Serendipita_A-I was amplified, compared with specimens in which these fungi were not detected (mean SLC by DS hyphae $=2.0 \%$ and $20.6 \%$, respectively; $\left.F_{1,46}=8.21, p=0.006\right)$. PCA similarly indicated negative associations between the frequencies of DS hyphae and those of Serendipita (Fig. 4), with these hyphae being absent from specimens from which the DNA of Serendipita_D, Serendipita_E or Serendipita_I was amplified, and DS hyphae occupying $2-5 \%$ of stem length when the other six groups of Serendipita were recorded in specimens. In contrast, PCA showed positive associations between the frequencies of DS hyphae and those of Cladophialophora_B and the Leotiomycetes member in G. inflata, the latter fungus and the Dothideomycetes representative in C. bicuspidata, and the members of the Chaetothyriales and Lecanoromycetes in B. trichophyllum (Fig. 4), with DS hyphae occupying 34-55\% of stem length when the DNA of these five groups of fungi was amplified from specimens. All but one of the specimens
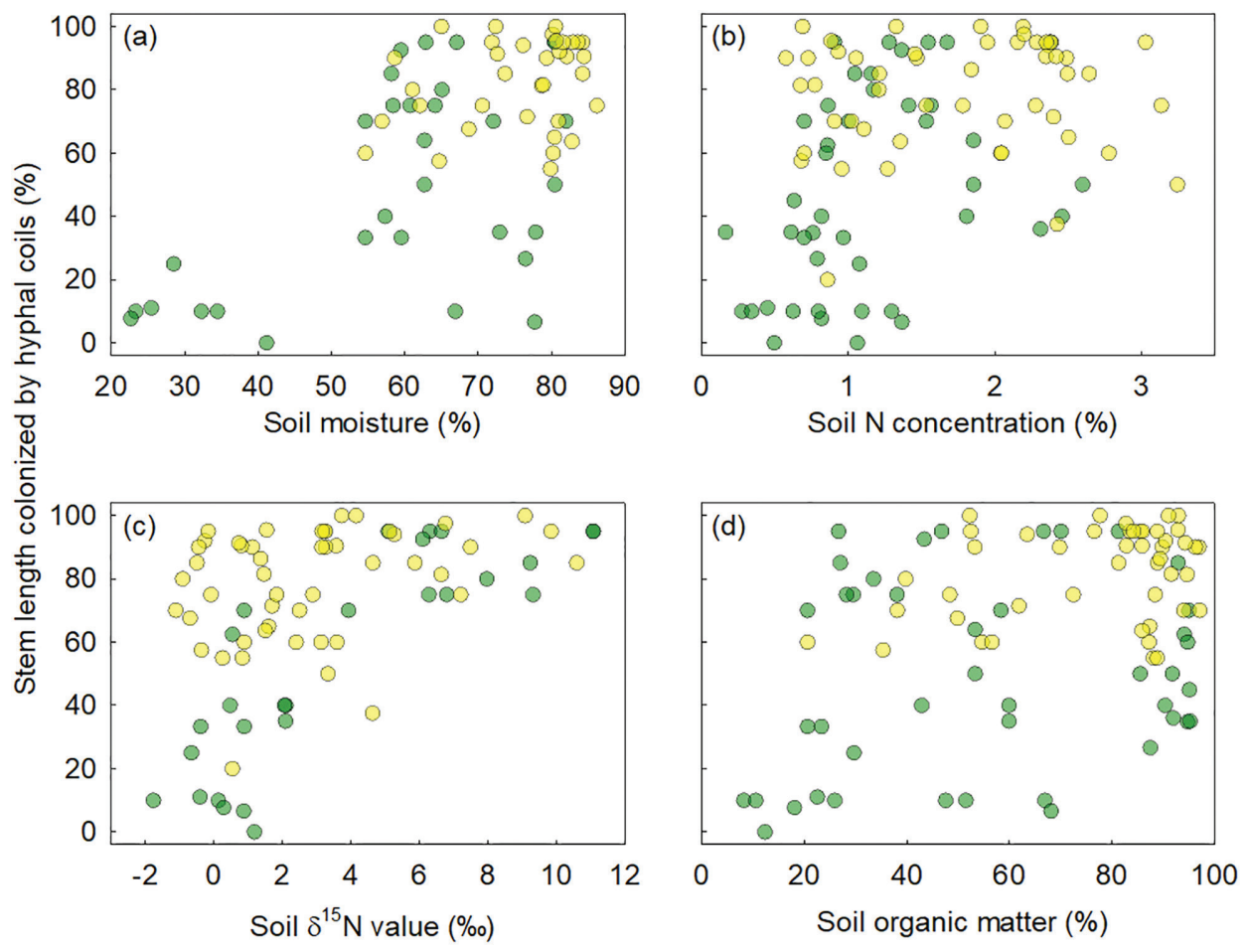

Key $\bigcirc$ Anastrophyllaceae $\bigcirc$ Lophoziaceae

Fig. 5 Percentages of SLC by hyphal coils in members of the Anastrophyllaceae and Lophoziaceae as a function of (a) soil moisture concentration, (b) soil $\mathrm{N}$ concentration, (c) soil $\delta^{15} \mathrm{~N}$ value and (d) soil organic matter concentration. Note that y axes are all scaled identically. 
from which the DNA of these fungi was amplified had been sampled from soils with $\mathrm{pH}$ values of 3.7-4.5.

\section{Edaphic factors as predictors of hyphal coil frequency}

Correlative analyses indicated that edaphic factors significantly predicted the frequency of hyphal coils in members of the Anastrophyllaceae and Lophoziaceae. When the observations for both families were combined, hyphal coil frequency was found to be positively correlated with the concentrations of soil moisture $(r=0.633, p<0.001)$, total nitrogen $(r=0.392, p<0.001)$ and organic matter $(r=$ $0.347, p=0.001)$, as well as with soil $\delta^{15} \mathrm{~N}$ value $(r=0.444$, $p<0.001$; Fig. 5a-d). Hyphal coil frequency across members of both families was also associated with soil total carbon concentration ( $r=0.272, p=0.007$; data not shown).

\section{Discussion}

The survey reported here shows for the first time that mycothalli occur north of the Arctic Circle and are apparently frequent on west Spitsbergen. Of the 13 leafy liverwort species that are abundant on Brøggerhalvøya and Blomstrandhalvøya (Arnell \& Mårtensson 1959), the rhizoids of 10 species were often colonized by hyphae, and the stems of nine species were frequently colonized by intracellular hyphal coils, a defining feature of the symbiosis (Boullard 1988; Read et al. 2000). The patterns of colonization observed in the tissues of these leafy liverwort species, which were each members of the Anastrophyllaceae, Cephaloziaceae, Cephaloziellaceae, Lophoziaceae or Scapaniaceae, were thus similar to those observed in members of these five families sampled from lower latitudes, such as species of Barbilophozia, Lophozia, Cephalozia, Cephaloziella, Diplophyllum and Scapania in temperate, tropical and Antarctic habitats (Duckett \& Read 1995; Upson et al. 2007; Bidartondo \& Duckett 2010; Newsham \& Bridge 2010; Kowal et al. 2018). In contrast, members of the Ptilidiaceae and Blepharostomataceae (Ptilidium ciliare and Blepharostoma trichophyllum, respectively) did not exhibit these patterns of colonization. Colonization by hyphal coils was absent from the stems of $P$. ciliare, from which rhizoids were apparently absent, corroborating the view that fungal symbionts enter liverwort tissues via the tips of rhizoid cells (Pressel et al. 2010). Despite the presence of colonized rhizoids on the stems of B. trichophyllum, hyphal coils only occasionally formed at the base of rhizoid cells in this species and did not proliferate further along the stem. This pattern of colonization is similar to that previously recorded for Calypogeia, in which cell wall ingrowths halt the growth of fungal hyphae beyond rhizoid bases (Němec 1904).
The data reported here, in addition to adding further weight to the argument that the Serendipitaceae has a global distribution (Newsham \& Bridge 2010; Weiß et al. $2011,2016)$, indicate that Serendipita mycobionts are frequent in the Anastrophyllaceae and Lophoziaceae, later-diverging hepatic families assigned to clade B of leafy clade II by Forrest et al. (2006). Previous studies using electron microscopy have shown the presence of heterobasidiomycetes with dolipore septa and imperforate parenthosomes-which were most probably members of Serendipita-forming tightly convoluted, intracellular hyphal coils in the tissues of liverworts in these families and in those of the Arnelliaceae, Jungermanniaceae, Geocalycaceae and Scapaniaceae (Read et al. 2000; Bidartondo \& Duckett 2010). The study here, based on epifluorescence microscopy and PCR amplification of fungal ribosomal RNA genes, closely corroborates these observations, with the frequency of Serendipita being positively associated with the abundance of intracellular hyphal coils, identical to those previously recorded in European and Antarctic Diplophyllum albicans, Schistochilopsis incisa, Barbilophozia hatcheri, Trilophozia quinquedentata and Lophoziopsis excisa (Bidartondo \& Duckett 2010; Newsham \& Bridge 2010; Newsham et al. 2014). The analyses here also indicate that Serendipita most probably does not form DS hyphae, with melanized hyphae being absent from, or present at very low levels in, specimens from which the DNA of the basidiomycete was amplified. Positive associations between the frequencies of Serendipita and hyphal colonization of rhizoid cells were also recorded. However, rhizoid colonization is most probably a poor predictor for the presence of the basidiomycete, as resynthesis experiments have shown other fungal taxa, such as Pezoloma ericae, to colonize rhizoids (Upson et al. 2007; Kowal et al. 2018).

Previous studies have noted that mycothalli formed between leafy liverworts and Serendipita tend to occur on well-drained soils that are rich in humus (Duckett et al. 2006; Bidartondo \& Duckett 2010), raising the possibility that underlying soil chemistry influences the formation of the symbiosis. The correlative analyses here confirm that intracellular hyphal coils are more frequent in the tissues of the Anastrophyllaceae and Lophoziaceae on soils with higher concentrations of moisture, organic matter, carbon and nitrogen. In addition, hyphal coils also frequently formed in the tissues of members of these families sampled from soils with $\delta^{15} \mathrm{~N}$ values of up to $11 \%$, associated with the input of marine-derived nitrogen from seabirds below bird cliffs (Zwolicki et al. 2016). Thus, as well as influencing the taxa of leafy liverworts that occur on the Brøggerhalvøya, such as the positive associations found between the occurrence of $B$. hatcheri and soil carbon and nitrogen concentrations (Wietrzyk-Pełka et al. 2020), 
edaphic factors also apparently determine the formation of mycothalli, as they do in mycorrhizal symbioses (Read 1991; Wubet et al. 2012). Although soil pH was not associated with the formation of hyphal coils, the analyses here suggest that $\mathrm{pH}$ value influences the occurrence of Serendipita in leafy liverwort tissues, with Gymnocolea inflata (Anastrophyllaceae) and Scapania undulata (Scapaniaceae), members of families colonized by the basidiomycete at lower latitudes (Rimington et al. 2020), apparently not associating with the mycobiont. Both species were sampled from mine tailings with a mean $\mathrm{pH}$ value of 4.5 , suggesting that Serendipita cannot tolerate strongly acidic conditions. This view is supported by a study showing that four out of six isolates of $S$. vermifera from orchid mycorrhizas grew less well at pH 4 than at pH 5-8 (Warcup 1988). The absence of ectomycorrhizas formed by the Sebacinaceae from strongly acidic ( $\mathrm{pH}$ 3.0-3.4) soils in northern Europe, compared with up to 13 ectomycorrhizas formed by the family in less acidic ( $\mathrm{pH} \leq 6.4)$ soils (Wubet et al. 2012), further suggests that fungi allied with Serendipita are unable to tolerate soils of high acidity.

Ascomycetes were frequently recorded in liverwort tissues from west Spitsbergen, where, in agreement with previous studies on Pezoloma ericae (Upson et al. 2007), they were apparently responsible for the formation of DS hyphae on stem surfaces. Despite previous studies showing that $P$. ericae associates with leafy liverworts, and notably members of the Cephaloziaceae and Cephaloziellaceae (Upson et al. 2007; Kowal et al. 2018), the fungus was not recorded in C. bicuspidata and C. varians, the members of these families sampled in our study. These liverwort species were instead colonized by members of the Dothideomycetes and Leotiomycetes, typically on acidic ( $\mathrm{pH} 4.5)$ mine tailings, with the best match for the latter mycobiont being a fungus present in Alaskan soils of pH value 4.4-4.7 (Deslippe et al. 2012). Nevertheless, P. ericae was recorded in Schljakovianthus quadrilobus, Sphenolobus minutus and B. hatcheri, raising the possibility that the fungus might form symbioses with members of the Anastrophyllaceae, such as the report of ascomycetes colonizing Barbilophozia barbata (Kottke et al. 2003). Whilst it is not possible to discount the possibility that the other ascomycetes recorded here are commensals with no symbiotic status, it is notable that two groups of Cladophialophora were recorded in Lophozia wenzelii, B. hatcheri and G. inflata. Cladophialophora has similarly been found to associate with species of Lophozia and Barbilophozia in North America and Antarctica (Davis \& Shaw 2008; Newsham \& Bridge 2010), suggesting that the genus may form symbioses with leafy liverworts, and particularly those in cold environments (Newsham et al. 2014). Given the culturability of Cladophialophora (Davey \& Currah 2007), we advocate that resynthesis experiments are conducted to determine the effects of the fungus on its liverwort hosts.

A recent literature survey estimated that $29 \%$ of 591 liverwort species in temperate and tropical habitats engage in symbioses with soil fungi (Rimington et al. 2020). Of the leafy liverworts, some $20 \%$ of species are colonized by ascomycetes, with just 5\% being colonized by basidiomycetes (Rimington et al. 2020). The data reported here for the ascomycetes fit well with these estimates, with three out of $13(23 \%)$ of liverwort species sampled from west Spitsbergen apparently associating with P. ericae, a known symbiont of leafy liverworts (Upson et al. 2007; Kowal et al. 2018). However, leafy liverwort-associated basidiomycetes of known symbiotic status - that is, predominantly Serendipita (Weiß et al. 2016)—were recorded in the tissues of $54 \%$ of the liverwort species studied here. The reason for this apparent order of magnitude increase in the frequency of leafy liverwort taxa associating with Serendipita on Spitsbergen is unclear. It is possible that the local environment, which is characterized by frequent subzero air temperatures, coupled with nine months of snow cover and the absence of direct sunlight for almost four months each year, selects for liverwort taxa that form mycothalli with these fungi. This seems plausible, given that the Lophoziaceae and Anastrophyllaceae account for 38-48\% of leafy liverwort communities in the Canadian Arctic and north-west Greenland (Damsholt 2007; Hassel et al. 2014). However, another, and not mutually exclusive, explanation for the abundance of mycothalli formed by Serendipita on Spitsbergen is that these mycobionts may confer benefits on their liverwort hosts in harsh environments, for example, by synthesizing osmolytes in planta that stabilize plasma membranes at low temperatures and confer freezing tolerance on the host (Acuña-Rodríguez et al. 2020). It is also possible that mycobionts may assist leafy liverworts in the acquisition of nutrients (Kowal et al. 2018), and, in particular, organic forms of nitrogen, which accumulate in Arctic soils (Boddy et al. 2008). Forthcoming studies will address this possibility.

\section{Conclusion}

We conclude that mycothalli are present north of the Arctic Circle, and that the symbiosis is apparently more frequent in locally abundant leafy liverworts on west Spitsbergen than it is at lower latitudes. Given the abundance in the Arctic of liverwort families that form the symbiosis (Konstantinova 2000; Damsholt 2007, 2013; Hassel et al. 2014) and the potential influence of mycobionts on the physiology of leafy liverworts, we advocate that further surveys should be made to ascertain the frequency of the symbiosis across the region. 


\section{Acknowledgements}

Fieldwork support was provided by Nick Cox, Guy Hillyard, Motoaki Tojo, Roger Worland, Lufttransport AS and staff of the Kings Bay company. The Governor of Svalbard permitted the collection of plants and soils. George Foot helped to process the DNA sequence data. Our much-valued colleague, the late Jiří Váňa (Charles University Prague), identified leafy liverwort specimens. Two anonymous reviewers made helpful comments on the submission. All are gratefully acknowledged.

\section{Disclosure statement}

The authors report no potential conflict of interest.

\section{Funding}

KKN and WPGC were supported by Natural Environment Research Council core funding to the British Antarctic Survey.

\section{References}

Acuña-Rodríguez I.S., Newsham K.K., Gundel P.E., TorresDíaz C. \& Molina-Montenegro M.A. 2020. Functional roles of microbial symbionts in plant cold tolerance. Ecology Letters 23, 1034-1048, doi: 10.1111/ele.13502.

Arnell S. \& Mårtensson O. 1959. A contribution to the knowledge of the bryophyte flora of w. Spitsbergen, and Kongsfjorden (King's Bay, $79^{\circ} \mathrm{N}$ ) in particular. Arkiv för Botanik 4, 104-164.

Asplund J. \& Wardle D.A. 2017. How lichens impact on terrestrial community and ecosystem properties. Biological Reviews 92, 1720-1738, doi: 10.1111/brv.12305.

Beck P.S.A., Kalmbach E., Joly D., Stien A. \& Nilsen L. 2005. Modelling local distribution of an Arctic dwarf shrub indicates an important role for remote sensing of snow cover. Remote Sensing of the Environment 98, 110-121, doi: 10.1016/j.rse.2005.07.002.

Bidartondo M.I. \& Duckett J.G. 2010. Conservative ecological and evolutionary patterns in liverwort-fungal symbioses. Proceedings of the Royal Society B 277, 485-492, doi: 10.1098/rspb.2009.1458.

Blaalid R., Kumar S., Nilsson R.H., Abarenkov K., Kirk P.M. \& Kauserud H. 2013. ITS1 versus ITS2 as DNA metabarcodes for fungi. Molecular Ecology Resources 13, doi: 10.1111/1755-0998.12065.

Boddy E., Roberts P., Hill P.W., Farrar J. \& Jones D.L. 2008. Turnover of low molecular weight dissolved organic C (DOC) and microbial C exhibit different temperature sensitivities in Arctic tundra soils. Soil Biology and Biochemistry 40, 1557-1566, doi: 10.1016/j.soilbio.2008.01.030.

Boullard B. 1988. Observations on the coevolution of fungi with hepatics. In K.A. Pyrozynski \& D.L. Hawksworth (eds.): Coevolution of fungi with plants and animals. Pp. 107-124. London: Academic Press.

Damsholt K. 2007. Liverworts of the Reindeer Preserve, Northwest Territories, Canada. Lindbergia 31, 88-100.

Damsholt K. 2013. The liverworts of Greenland. Lund: Nordic Bryological Society.

Davey M.L. \& Currah R.S. 2007. A new species of Cladophialophora (hyphomycetes) from boreal and montane bryophytes. Mycological Research 111, 106-116, doi: 10.1016/j.mycres.2006.10.004.

Davis E.C. \& Shaw A.J. 2008. Biogeographic and phylogenetic patterns in diversity of liverwort-associated endophytes. American Journal of Botany 95, 914-924, doi: 10.3732/ajb.2006463

Deslippe J.R., Hartmann M., Simard S.W. \& Mohn W.W. 2012. Long-term warming alters the composition of Arctic soil microbial communities. FEMS Microbiology Ecology 82, 303-315, doi: 10.1111/j.1574-6941.2012.01350.x

Duckett J.G. \& Read D.J. 1995. Ericoid mycorrhizas and rhizoid-ascomycete associations in liverworts share the same mycobiont-isolation of the partners and resynthesis of the associations in vitro. New Phytologist 129, 439-477, doi: 10.1111/j.1469-8137.1995.tb04315.x.

Duckett J.G., Russell J. \& Ligrone R. 2006. Basidiomycetous endophytes in jungermannialean (leafy) liverworts have novel cytology and species-specific host ranges: a cytological and experimental study. Canadian Journal of Botany 84, 1075-1093, doi: 10.1139/b06-073.

Forrest L.L., Davis E.C., Long D.G., Crandall-Stotler, B., Clark A. \& Hollingsworth M.L. 2006. Unraveling the evolutionary history of the liverworts (Marchantiophyta): multiple taxa, genomes and analyses. The Bryologist 109, 303-334.

Frisvoll A.A. \& Elvebakk A. 1996. Part 2. Bryophytes. In A. Elvebakk \& P. Prestrud (eds): A catalogue of Svalbard plants, fungi, algae and cyanobacteria. Norsk Polarinstitutt Skrifter 198. Pp. 57-172. Oslo: Norwegian Polar Institute.

Gardes M. \& Bruns T.D. 1993. ITS primers with enhanced specificity for Basidiomycetes-application to the identification of mycorrhizae and rusts. Molecular Ecology 2, 113-118, doi: 10.1111/j.1365-294X.1993.tb00005.x.

Hanssen-Bauer I., Førland E.J., Hisdal H., Mayer S., Sandø A.B. \& Sorteberg A. (eds.) 2019. Climate in Svalbard 2100-a knowledge base for climate adaptation. NCCS Report 1/2019. Doi: 10.13140/RG.2.2.10183.75687. Oslo: Norwegian Centre for Climate Services.

Harley J.L. \& Waid J.S. 1955. A method of studying active mycelia on living roots and other surfaces in the soil. Transactions of the British Mycological Society 38, 104-118, doi: 10.1016/S0007-1536(55)80022-8.

Hassel K., Zechmeister H. \& Prestø T. 2014. Mosses (Bryophyta) and liverworts (Marchantiophyta) of the Zackenberg Valley, northeast Greenland. Lindbergia 37, 66-84, doi: 10.25227/linbg.01051.

Konstantinova N.A. 2000. Analiz arealov pečenočnikov severa Golarktiki. (Distribution patterns of the north Holarctic hepatics.) Arctoa 9, 29-94, doi: 10.15298/arctoa.09.06. (In Russian with English abstract.)

Kottke I., Beiter A., Weiß M., Haug I., Oberwinkler F. \& Nebel M. 2003. Heterobasidiomycetes form symbiotic associations 
with hepatics: Jungermanniales have sebacinoid mycobionts while Aneura pinguis (Metzgeriales) is associated with a Tulasnella species. Mycological Research 107, 957-968, doi: 10.1017/S0953756203008141.

Kowal J., Pressel S., Duckett J.G., Bidartondo M.I. \& Field K.J. 2018. From rhizoids to roots? Experimental evidence of mutualism between liverworts and ascomycete fungi. Annals of Botany 121, doi: 10.1093/aob/mcx 126.

McGonigle T.P., Miller M.H., Evans D.G., Fairchild G.L. \& Swann J.A. 1990. A new method which gives an objective measure of colonization of roots by vesicular-arbuscular mycorrhizal fungi. New Phytologist 155, 495-501, doi: 10.1111/j.1469-8137.1990.tb00476.x.

Němec B. 1904. Die mykorrhiza von Calypogeia trichomanes. (The mycorrhiza of Calypogeia trichomanes.) Beitrage Botanisches Zentralblatte 16, 253-268.

Newsham K.K. \& Bridge P.D. 2010. Sebacinales are associates of the leafy liverwort Lophozia excisa in the southern maritime Antarctic. Mycorrhiza 20, 307-313, doi: 10.1007/ s00572-009-0283-9.

Newsham K.K., Goodall-Copestake W.P., Ochyra R. \& Váňa, J. 2014. Mycothalli of the hepatic Barbilophozia hatcheri in Antarctica: distribution and identities of mycobionts. Fungal Ecology 11, 91-99, doi: 10.1016/j. funeco.2014.05.001.

Newsham K.K., Upson R. \& Read D.J. 2009. Mycorrhizas and dark septate endophytes in polar regions. Fungal Ecology 2, 10-20, doi: 10.1016/j.funeco.2008.10.005.

Nilsson R.H., Tedersoo L., Ryberg M., Kristiansson E., Hartmann M., Unterseher, M., Porter T.M., Bengtsson-Palme J., Walker D.A., de Sousa F., Gamper H.A., Larsson E., Larsson K.-H., Kõljalg U., Edgar R.C. \& Abarenkov K. 2015. A comprehensive, automatically updated fungal ITS sequence dataset for reference-based chimera control in environmental sequencing efforts. Microbes and Environment 30, 145-150, doi: 10.1264/jsme2.me14121.

Pressel S., Bidartondo M.I., Ligrone R. \& Duckett J.G. 2010. Fungal symbioses in bryophytes: new insights in the twenty first century. Phytotaxa 9, 238-253, doi: 10.11646/ phytotaxa.9.1.13.

Read D.J. 1991. Mycorrhizas in ecosystems. Experientia 47, 376-391, doi: 10.1007/BF01972080.

Read D.J., Duckett J.G., Francis R., Ligrone R. \& Russell A. 2000. Symbiotic fungal associations in 'lower' land plants. Philosophical Transactions of the Royal Society of London B 355, 815-831, doi: 10.1098/rstb.2000.0617.

Rimington W.R., Duckett J.G., Field K.J., Bidartondo M.I. \& Pressel S. 2020. The distribution and evolution of fungal symbioses in ancient lineages of land plants. Mycorrhiza 30 , 23-49, doi: 10.1007/s00572-020-00938-y.

Rimington W.R., Pressel S., Duckett J.G., Field K.J. \& Bidartondo M.I. 2019. Evolution and networks in ancient and widespread symbioses between Mucoromycotina and liverworts. Mycorrhiza 29, 551-565, doi: 10.1007/s00572-019-00918-x.

Söderström L., Hagborg A., von Konrat M., BartholomewBegan S., Bell D., Briscoe L., Brown E., Cargill D.C.,
Costa D.P., Crandall-Stotler B.J., Cooper E.D., Dauphin G., Engel J.J., Feldberg K., Glenny D., Gradstein S.R., He X., Heinrichs J., Hentschel J., Ilkiu-Borges A.L., Katagiri T., Konstantinova N.A., Larraín J., Long D.G., Nebel M., Pócs T., Felisa Puche F., Reiner-Drehwald E., Renner M.A.M., Sass-Gyarmati A., Schäfer-Verwimp A., Moragues J.G.S., Stotler R.E., Sukkharak P., Thiers B.M., Uribe J., Váňa J., Villarreal J.C., Wigginton M., Zhang L. \& Zhu R.-L. 2016. World checklist of hornworts and liverworts. PhytoKeys 59, 1-821, doi: 10.3897/phytokeys.59.6261.

Stotler R.E. \& Crandall-Stotler, B. 2017. A synopsis of the liverwort flora of North America north of Mexico. Annals of the Missouri Botanical Garden 102, 574-709, doi: 10.3417/2016027.

Upson R., Read D.J. \& Newsham K.K. 2007. Widespread association between the ericoid mycorrhizal fungus Rhizoscyphus ericae and a leafy liverwort in the maritime and sub-Antarctic. New Phytologist 176, 460-471, doi: 10.1111/j.1469-8137.2007.02178.x.

Warcup J.H. 1988. Mycorrhizal associations of isolates of Sebacina vermifera. New Phytologist 110, 227-231, doi: 10.1111/j.1469-8137.1988.tb00256.x.

Weiß M., Sýkorová Z., Garnica S., Riess K., Martos F., Krause C., Oberwinkler F., Bauer R. \& Redecker D. 2011. Sebacinales everywhere: previously overlooked ubiquitous fungal endophytes. PLoS One 6, el6793, doi: 10.1371/ journal.pone.0016793.

Weiß M., Waller F., Zuccaro A. \& Selosse M.-A. 2016. Sebacinales-one thousand and one interactions with land plants. New Phytologist 211, 20-40, doi.org/10.1111/ nph.13977.

White T.J., Bruns T.D., Lee S.B. \& Taylor J.W. 1990. Amplification and direct sequencing of fungal ribosomal RNA genes for phylogenetics. In M.A. Innis et al. (eds): PCR protocols: a guide to methods and applications. Pp. 315321. Berkeley, CA: Academic Press.

Wietrzyk-Pełka P., Cykowska-Marzencka B., Maruo F., Syzmański W. \& Węgrzyn M.H. 2020. Mosses and liverworts in the glacier forelands and mature tundra of Svalbard (High Arctic): diversity, ecology, and community composition. Polish Polar Research 41, 151-186, doi: 10.24425/ppr.2020.133011.

Winther J.-G., Godtliebsen F., Gerland S. \& Isachsen P.A. 2002. Surface albedo in Ny-Ålesund, Svalbard: variability and trends during 1981-1997. Global and Planetary Change 32, 127-139, doi: 10.1016/S0921-8181(01)00103-5.

Wubet T., Christ S., Schöning I., Boch S., Gawlich M., Schnabel B., Fischer M. \& Buscot F. 2012. Differences in soil fungal communities between European beech (Fagus sylvatica L.) dominated forests are related to soil and understorey vegetation. PLoS One 7, e47500, doi: 10.1371/ journal.pone.0047500.

Zwolicki A., Zmudczyńska-Skarbek K., Matuła J., Wojtuń B. \& Stempniewicz L. 2016. Differential responses of Arctic vegetation to nutrient enrichment by plankton- and fish-eating colonial seabirds in Spitsbergen. Frontiers in Plant Science 7, 1959, doi: 10.3389/fpls.2016.01959. 